Ораева Б.Н., Атаев О.Г., Коротенко Т.И.
ПУЛЬСОВОЕ ДАВЛЕНИЕ КАК ПРЕДИКТОР ФОРМИРОВАНИЯ ГИПЕРТЕНЗИИ

Ораева Бахаргуль Нурмаммедовна, аспирант,

Госпиталь с научно-клиническим центром кардиологии 7440оо, Туркменистан, Ашгабат, ул.Атамурада Ниязова, д. 192 e-mail: bahar641@mail.ru

Атаев Овезмырат Гурбанмырадович, студент 5 курса, Белгородский государственный национальный исследовательский университет 308015 г. Белгород, ул. Победы, д. 85 e-mail: atayev.o.g@gmail.com

Коротенко Татьяна Игоревна, врач-интерн,

Белгородский государственный национальный исследовательский университет 308015 г. Белгород, ул. Победы, д. 85 tat.korotenko26@yandex.ru

\title{
Аннотация
}

$\prod^{\mathrm{p} s}$ робы с дозированными физическими нагрузками, среди которых в силу простоты и диагностической ценности наиболее распространена велоэргометрия (ВЭМ), позволяют получить важную информацию об адаптационных возможностях и физической работоспособности организма. ВЭМ позволяет выявить изменений сердечно-сосудистой деятельности еще на функциональном уровне и обладает прогностическим значением. В работе проведена сравнительная оценка результатов, пульсового артериального давления (ПАД), полученных при исследовании функциональной активности сердечно-сосудистой системы с помощью ВЭМ, в сопоставлении с результатами инструментальных методов исследования, таких как: эхокардиография (ЭхоКГ), дуплексное сканирование сонных артерий, допплер-ЭхоКГ у 62 мужчин с высоким нормальным артериальным давлением (АД) и с пограничным АД. Выявлены следующие закономерности: у большинства исследуемых пациентов с повышенным ПАД при субмаксимальной частоте сердечных сокращений (ЧСС) на высоте нагрузки имеются: гипертрофия левого желудочка (ГЛЖ), дигиталисная дисфункция (ДДФ), рестриктивное нарушение кровенаполнения и выраженные изменения в сонных артериях в виде атеросклероза.

$\mathrm{K}$

лючевые слова: сердечно-сосудистая система (ССС), велоэргометрия (ВЭМ), прогностическое значение, функциональное состояние, пульсовое артериальное давление (ПАД), атеросклероз, гипертрофия левого желудочка, диастолическая дисфункция, рестриктивное нарушение кровенаполнения. 
Orayeva B.N., Atayev O.G., Korotenko T.I.

\section{PULSE PRESSURE} AS A PREDICTOR OF THE DEVELOPMENT OF HYPERTENSION

Oraeva Bakhargul Nurmammedovna, Postgraduate Student

Hospital with Scientific Clinical Center of Cardiology

192 Atamurad Niyazov St., Ashgabat, 74400o, Turkmenistan

e-mail: bahar641@mail.ru

Korotenko Tatyana Igorevna, Internship Doctor

Belgorod State National Research University

85 Pobedy St., 308015, Belgorod, Russia

e-mail: tat.korotenko26@yandex.ru

Ataev Ovezmyrat Gurbanmyradovich, Fifth-year Student

Belgorod State National Research University

85 Pobedy St., 308015, Belgorod, Russia

e-mail: atayev.o.g@gmail.com

\section{Abstrakt}

Qamples with exercise stress include bicycle ergometry (BEM) used due to its simplicity $\checkmark$ and diagnostic value. BEM provides important information about the adaptive capacity and physical capability of the body and is used to detect changes in the cardiovascular activity on a functional level, thus, possessing a prognostic value. We have compared the results of pulse pressure (PAP) obtained in the study of the functional activity of the cardiovascular system via VEM with the results of instrumental methods, including echocardiography (echocardiography), duplex scanning of carotid artery, Doppler echocardiography in 62 men with high normal blood pressure (BP) or borderline blood pressure. Thus, we have revealed the following consistent patterns: the majority of the studied patients with elevated PAP during submaximal heart rate (HR) at the height of the load demonstrated left ventricular hypertrophy (LVH), digitalis dysfunction (DD), restrictive failure of blood supply, and pronounced changes in the carotid arteries in the form of atherosclerosis.

K functional status; pulse pressure (PAP); atherosclerosis; left ventricular hypertrophy (LVH); diastolic dysfunction (DD); restrictive violation blood supply. 
Введение. Исследование функции сердечно-сосудистой системы в покое часто не позволяет составить достаточно полное представление об ее функциональном состоянии. Этим и объясняется широкая распространенность нагрузочных проб в кардиологии. [1] Пробы с дозированными физическими нагрузками, среди которых в силу простоты и диагностической ценности наиболее распространена велоэргометрия (ВЭМ), позволяющая получить важную информацию об адаптационных возможностях и физической работоспособности организма, выявить изменения сердечно-сосудистой деятельности еще на функциональном уровне и обладает прогностическим значением $[2,3]$. В последнее время внимание исследователей все чаще привлекают пациенты с высоким нормальным артериальным давлением (АД) или с пограничным артериальным давлением, составляющие группу риска формирования клинически выраженной артериальной гипертензии (АГ).

Цель работы: доказать методом сравнительной характеристики прогностическое значение ПАД, при формировании артериальной гипертензии.

\section{Материалы и методы исследования}

В амбулаторных условиях проведено обследование 62 мужчин в возрасте 31-45 лет (в сред-

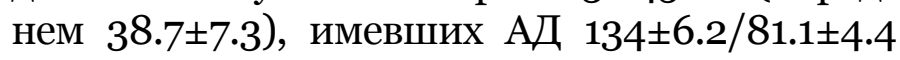
мм. рт. ст. Всем пациентам проведена эхокардиография (ЭхоКГ), дуплексное сканирование сонных артерий, а также велоэргометрия (ВЭМ) до достижения субмаксимальной ЧСС с особым вниманием не только на «ишемическую» депрессию сегмента ST на ЭКГ, но и на реакцию АД на физическую нагрузку. Отдель- но анализировались параметры систолического, диастолического и пульсового АД (САД, ДАД, ПАД) в исходном состоянии и на высоте пробы. Выраженность гипертрофии левого желудочка (ГЛЖ) определялось по индексу массы миокарда левого желудочка (ИММЛЖ) рассчитывали как отношение ММЛЖ к площади поверхности тела предложенной R.Devereux и N.Reichek, наличие диастолической дисфункции (ДДФ) - по характеру трансмитрального кровотока при допплер-ЭхоКГ [6,7]. Наличие атеросклеротических изменений считали доказанными при обнаружении на стенке сонной артерии атеросклеротических бляшек при их дуплексном сканировании [4].

В результате проведенного исследования, всех пациентов разделили на две группы, как видно на рис. 1, выявили, что из 62 мужчин у 38 (61.3\%) обследованных САД на высоте нагрузки не превышало 190.7 \pm 10.6 мм рт.ст. (что составило 1 группу), у остальных 24 (38.7\%) пациентов САД составило 218.4 \pm 16.6 мм рт.ст. (2 группа пациентов). Одновременно в каждой группе анализировали показатели ПАД, в результате чего было выделено две подгруппы в каждой группе.

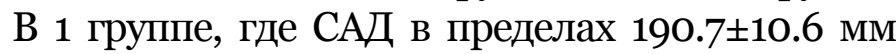
рт.ст. выделено: 1 А группа без увеличения ПАД (менее 56 мм. рт. ст.) - 30 обследуемых (78.9\%) и 1Б группа -12 (21.1\%), у которых на высоте нагрузки ПАД превышало пограничное значение ( $\geq 56$ мм. рт. ст.), аналогично и во 2 группе выделенны 2 подгруппы, у которых САД в пределах $218.4 \pm 16.6$ мм рт.ст. при физической нагрузке на ВЭМ - 2А группа без увеличения ПАД-12 обследуемых (50\%), и 2Б группа - 8 (50.0\%), лица у которых на высоте нагрузки ПАД превышало пограничное значение ( $\geq 56$ мм. рт. ст.).
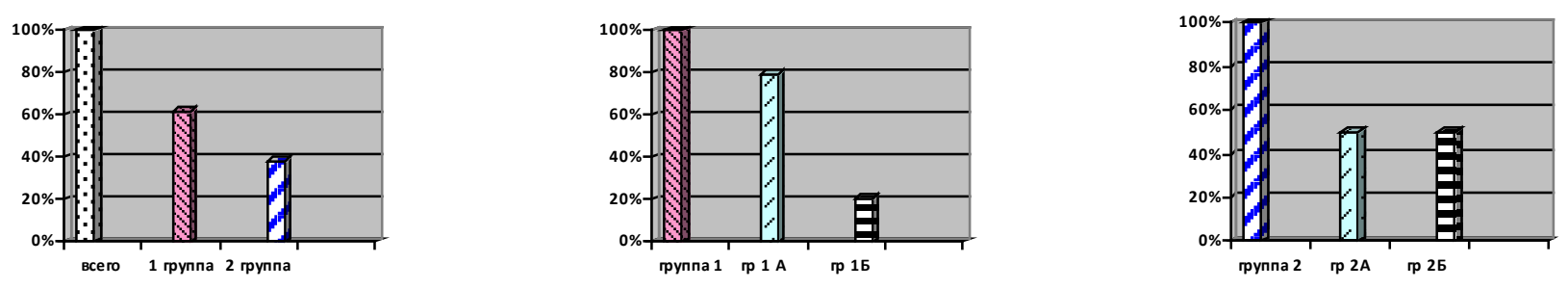

\section{Рисунок 1. Основнье әруппь исследования The main research groups}

\section{Результаты и их обсуждение}

Сопоставление наличия атеросклеротических бляшек в сонных артериях в 1 и 2 группах наблюдения показало, что они имелись у 4 пациентов (50.0\%) 1Б подгруппы, где САД на высоте нагрузки не превышало $190.7 \pm 10.6$ мм рт.ст. и соответственно в группе, где САД составило 218.4 \pm 16.6 мм рт.ст., имелись у всех 12 пациентов (100\%) 2Б подгруппы. В то же время у остальных лиц $1 \mathrm{~A}$ 
и 2А группы наличия атеросклеротических бляшек в сонных артериях прослеживались у 8 (26.6\%) и 7 (58.3\%) пациентов. Особое внимание привлекают данные выявления ГЛЖ среди лиц с различной реакцией ПАД на физическую нагрузку. Так, у пациентов $1 \mathrm{~A}$ группы с нормальной реакцией АД при ВЭМ
ГЛЖ, выявлена в 14 (47.0\%) наблюдений, а во 2А-й группе-у 10 (83.0\%). В то же время учет только повышения ПАД показал, что ГЛЖ в 1Б и 2Б группах имелась практически у всех обследованных, соответственно у 7 (89.5\%) и 11 (95.8\%).(рис. 2).

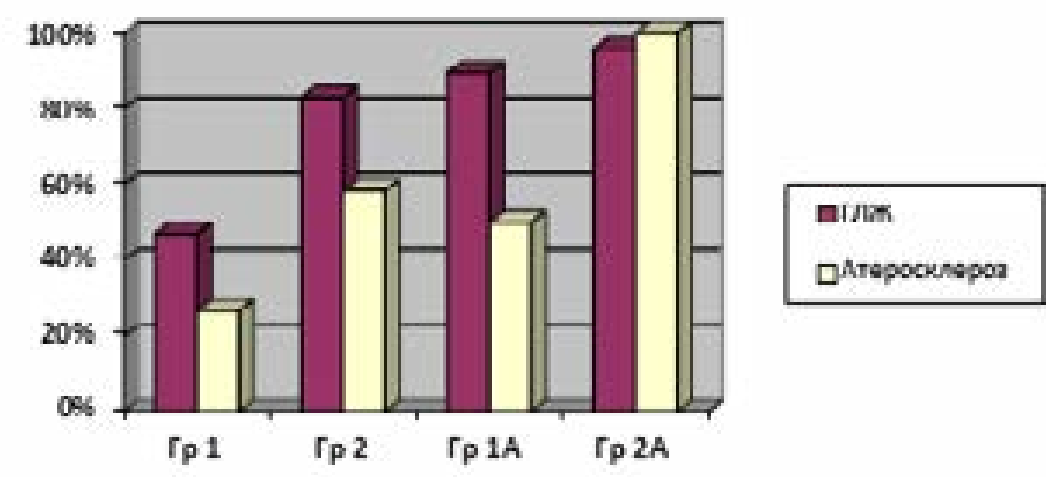

\section{Рис.2 Частота ГЛЖ и атеросклероза в исследуемъх әруппах Quantitative detection of $L V H$ and atherosclerosis}

Исследование на наличие диастолической дисфункции в 4 подгруппах позволило выявить интересную закономерность. Зависимость ДДФ от значения ПАД, наблюдаемые в 1Б и 2Б подгруппах с повышенным критическим значением ( $\geq 56$ мм рт. ст.) ПАД был выявлен 100\% показатель наличия ДДФ, т.е. у всех пациентов этих групп. В тоже время в подгруппах 1А и 2А, где ПАД не достигал критических значений на фоне нагрузки, лишь у части пациентов было обнаружено диастолическая дисфункция - 1A группы у 11 (36.8\%) и 10 (87.5\%) во 2А группе

Необходимо подчеркнуть, что повышение ПАД ассоциировалось с наличием рестриктивных нарушений кровенаполнения левого желудочка, выявленных в подгруппах соответственно у 1 Б - 37.5\% (3) и 2Б $58.3 \%$ (7) обследованных (рис.3). А у пациентов 1 А и 2 А у которых ПАД был $\leq 56$ мм рт. ст. таких нарушений выявлено не было.

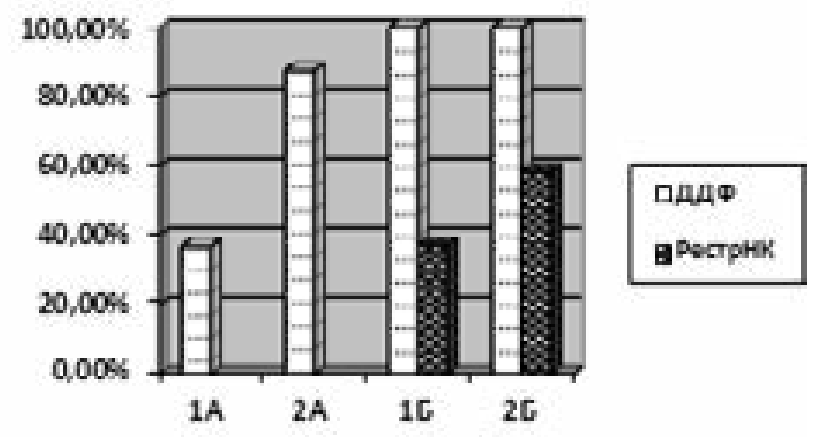

\section{Рисунок 3. Частота ДДФ и рестриктивного наруиения кровенаполнения Quantitative detection of DDF and restrictive disorders of blood supply}

\section{Выводы}

1. Подъем ПАД при ВЭМ выше критических значений (>56 мм), позволяет выявить категории пациентов, у которых имеются ГЛЖ и выраженные изменения в сонных артериях в виде атеросклероза.

2. Завышенное пульсовое давление при субмаксимальном ЧСС на фоне физической нагрузки служит предиктором формирования и развития гипертензии.

3. Изменения пульсового артериального давление при ВЭМ - является дешевым и в то же время доступным методом диагностики, а также профилактики возникновения сердечно-сосудистых заболеваний. 


\section{ЛИТЕРАТУРА:}

1. Алёхин М. Н., Еремина Н. В., Радова Н. Ф. Функциональные нагрузочные пробы у больных с подозрением на нестабильную стенокардию. 2012. Терапевтический архив , № 4: 63-68.

2. Аронов Д. М., Лупанов В. П. 2002. Функциональные пробы в кардиологии. М.: МЕДпресс-информ.

3. Корытников К. И. Кардиология. Возможность оценки правожелудочковой недостаточности при ишемической болезни сердца по данным импульсной допплерографии крупных печеночных вен, 1995. № 1: 57-59.

4. Орлова Я. А., Агеев Ф.Т. Жесткость артерий как интегральный показатель сердечно-сосудистого риска: физиология, методы оценки и медикаментозной коррекции2006. Сердце. №2: 65-69.
5. Фейгенбаум Х. 1995. Эхокардиография: Пер. с англ. Под ред. В.В. Митькова. 1999. Видар. 512.

6. Joint National Committee (JNCVI). 1997. Arch.Inter.Med. №157: 2413-2446

7. Nakazato R., Tamarappoo B.K., Smith T.W. et al. Assessment of left ventricular regional wall motion and ejection fraction with low-radiation dose helical dual-source CT: comparison to two-dimensional echocardiography2011. Cardiovasc Comput Tomogr. N 3: 149-157.

\section{REFERENCES:}

1. AAlokhin M.N., Yeremina N.V., Radova N.F. Functional exercise testing in patients with suspected unstable angina. 2012. Therapeutic archive. №4. Pp. 63-68.

2. Aronov D.M., LupanovV.P.2002. Functional Tests in Cardiology. M.: MEDpress-inform.

3. Korytnikov K.I. The ability to assess right ventricular failure in coronary heart disease according to the pulsed Doppler major hepatic veins. 1995. Cardiology. №1. Pp. 57-59.

4. Orlova Y.A., Ageyev F.T. The stiffness of the arteries as an integral indicator of cardiovascular risk: physiology, methods of assessment and medical correction. 2006. The Heart. №2. Pp. 65-69.
5. Feygenbaum H. 1995. Echocardiography. Transl. from English, ed. by V.V. Mit'kova. 1999. Vidar. $512 \mathrm{p}$.

6. Joint National Committee (JNCVI) 1997. Arch.Inter.Med. №157: 2413-2446

7. Nakazato R., Tamarappoo B.K., Smith T.W. et al. Assessment of left ventricular regional wall motion and ejection fraction with low-radiation dose helical dualsource CT: comparison to two-dimensional echocardiography2011. Cardiovasc Comput Tomogr. №3.Pp. 149-157. 